\title{
HecoUSAL: Huertos escolares ecológicos comunitarios USAL
}

\author{
Ángela Barrón Ruiz; José Manuel Muñoz Rodríguez
}

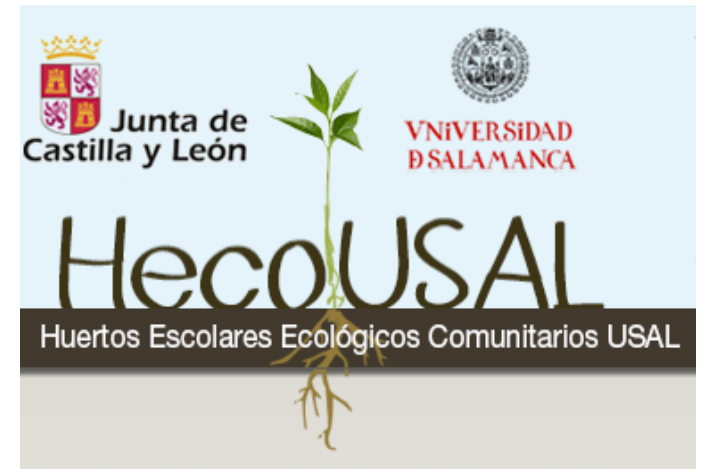

$\mathrm{H}$

ECOUSAL ES UNA Red de Huertos Escolares Comunitarios en centros de Educación Infantil, Primaria, Secundaria y Educación Especial, de la ciudad y provincia de Salamanca. Este proyecto se puso en marcha en el curso 2013-2014 por los profesores de la Facultad de Educación, Ángela Barrón y José Manuel Muñoz, integrando metodologías de Aprendizaje y Servicio (ApS).

HecoUSAL nació para atender una necesidad social como es la escasa presencia de programas transversales de Educación Ambiental para la sostenibilidad, en los centros escolares de la ciudad de Salamanca.

Se plantean diferentes objetivos:

- Formar profesionales comprometidos con la mejora social y con competencias en sostenibilidad.

- Mejorar su formación a través de la integración de nuevos métodos educativos basados en el ApS, estableciendo alianzas con entidades sociales para prestar un servicio social a los centros escolares.

- Contribuir a mejorar la Educación Ambiental y la cultura de la sostenibilidad en los centros escolares, así como a la formación del profesorado. 
- Activar redes de colaboración entre profesores universitarios con servicios y colectivos universitarios, centros de enseñanza infantil, primaria, secundaria y de educación especial, con fundaciones sociales y con administraciones públicas.

En este proyecto trabajan alumnos de las titulaciones de Pedagogía, Educación Social, Ciencias Ambientales y del Máster de Estudios Avanzados de Educación en la Sociedad Global, así como voluntarios universitarios.

El desarrollo y ejecución de las actividades se articulan en torno a tres ejes:

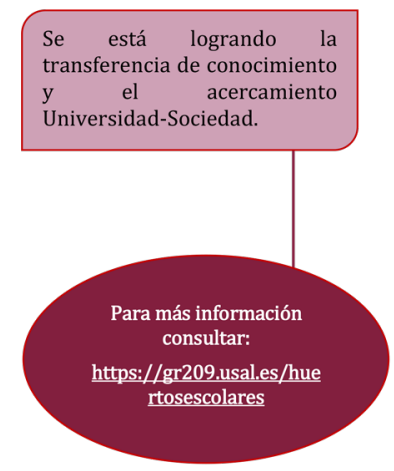

a) Diseño, ejecución y mantenimiento de huertos escolares ecológicos en los centros escolares. En esta línea de trabajo es fundamental la aportación de las dos Fundaciones colaboradoras (Fundación Tormes EB y Fundación Asprodes).

b) Integración curricular del huerto en todos los cursos de cada centro escolar. En este caso es fundamental la aportación de los profesores y alumnos universitarios.

c) Difusión social y académica del proyecto. Para ello es imprescindible el compromiso de la Comisión Ambiental del centro escolar y de los profesores universitarios.

La divulgación se ha realizado mediante los blogs de los centros, redes sociales, la web de la Red, notas de prensa, comunicaciones, publicaciones, presentaciones a concursos nacionales, presentaciones en radio y cursos de formación.

Para el seguimiento y evaluación se utilizan:

- Encuestas online para estudiantes universitarios, directivos de centros escolares y participantes.

- Seminarios de evaluación.

- Informes de los estudiantes.

- Memorias anuales de los directores de los centros.

- Seguimiento y difusión de las actividades realizadas a través de los blogs de los huertos, reunidos todos en el portal de la red.

Se han obtenido resultados altamente satisfactorios: una alta valoración de los estudiantes y participantes, la generación de huertos escolares, con sus respectivos blogs y comisiones ambientales; y un programa en el que destaca el enfoque comunitario, participativo y de sensibilización social para la sostenibilidad.

En cuanto a innovación destacan:

- La creación y mantenimiento de 18 huertos escolares ecológicos, con perspectiva de continuidad, que ayudan a transformar la cultura escolar en una cultura más comunitaria.

- El refuerzo de la innovación educativa, tanto en educación universitaria como en la escolar y de una educación ambiental más comunitaria, comprometida con los ODS de la Agenda 2030 y la cultura de la sostenibilidad.

- La vinculación de la docencia con la responsabilidad social, la sostenibilidad y la transferencia de conocimiento universitario a la sociedad. 